\title{
Review of fluid and control technology of hydraulic wind turbines
}

\section{(C) The Author(s) 2017. This article is published with open access at link.springer.com and journal.hep.com.cn}

\begin{abstract}
This study examines the development of the fluid and control technology of hydraulic wind turbines. The current state of hydraulic wind turbines as a new technology is described, and its basic fluid model and typical control method are expounded by comparing various study results. Finally, the advantages of hydraulic wind turbines are enumerated. Hydraulic wind turbines are expected to become the main development direction of wind turbines.
\end{abstract}

Keywords wind turbine, hydraulic system, fluid model, control technology

\section{Introduction}

Modern wind turbines typically adopt either a doubly fed induction generator whose main drive is a step-up gearbox, or a multi-level permanent-magnet synchronous generator (PMSG), which is driven directly without a gear. The selfexcitation characteristic of the multi-level PMSG enables a system to maintain high efficiency under high power. Thus, the multi-level PMSG is generally considered the ideal choice for variable-speed wind power generation [1-9]. However, hydraulic wind turbines present unique advantages in terms of the efficiency and reliability of wind power. First, hydraulic systems forgo the bulky gearbox and reduce the difficulty of manufacturing large-scale wind power generators [10]. Second, the hydraulic systems of hydraulic wind turbines possess a high power-weight ratio [11]. Finally, hydraulic systems can adjust the reduction gear ratio in a timely manner, adopt an electrically excited synchronous generator, eliminate the rectifier-inverter device, improve power generation efficiency, and ease

Received October 16, 2016; accepted January 3, 2017

Maolin CAI, Yixuan WANG, Zongxia JIAO ( $₫)$, Yan SHI ( $($ )

School of Automation Science and Electrical Engineering, Beihang University, Beijing 100191, China

E-mail: zxjiao@buaa.edu.cn; yesoyou@gmail.com the maintenance of wind turbines [12]. The research and development of hydraulic wind turbines has been carried out in many countries.

\section{Development of hydraulic wind turbines}

Figure 1 shows the main drive system of a typical hydraulic wind turbine, which mainly consists of a wind turbine, a fixed-quantity pump and variable hydraulic motor system, a synchronous generator, the control system of the power generator. A wind turbine transforms wind energy into mechanical energy, which is in turn converted into hydraulic energy by the movement of the pump. After the staircase energy is transferred, hydraulic energy is transferred to the variable motor to create mechanical energy. The variable motor drives the excited synchronous generator to convert hydraulic energy into electrical energy.

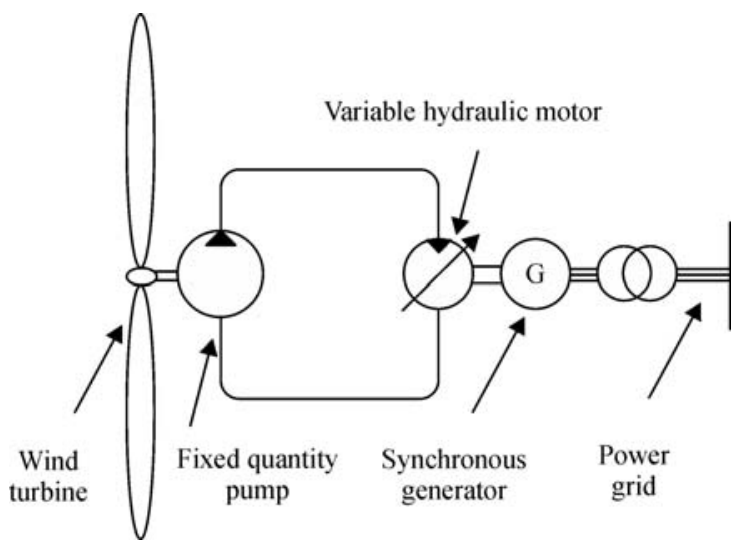

Fig. 1 Diagram of a hydraulic wind turbine

Many companies and research institutions have studied hydraulic wind turbines with this structure. The ChapDrive Company in Norway in 2007 and the Eaton Corporation in the US in 2010 developed hydraulic wind turbines 
equipped with a fixed-quantity pump and variable hydraulic motor system with high power and low power, respectively. These wind turbines were made of floormounted variable hydraulic motors and excited synchronous generators. High-pressure oil passed through the pipeline, drove the variable motor to gain a stable speed, and drove the excited synchronous generator to operate under a synchronous speed. These turbines satisfied the frequency requirements of the grid power [13,14]. In 2009, Artemis Intelligent Power Ltd. in Scotland completed a 1.5 MW hydraulic wind turbine model $[13,15]$ (Fig. 2). The company adopted a fixed-quantity pump and variable hydraulic motor system with a piston cylinder valve to control the flow, and its transmission efficiency can reach up to $90 \%$, which is approximate to that of the traditional gearbox [16]. In 2010, RWTH Aachen University in Germany constructed a hydraulic wind turbine platform (Fig. 3) and performed comparison analyses of theoretical simulation and experimental data $[17,18]$. They found that the fixed-quantity pump and variable hydraulic motor system can restrain the effect of wind speed fluctuations and achieve an average efficiency of up to $85 \%$ or higher. In 2009, Chen and Zhou [19] from Lanzhou, China, proposed a strategy for increasing the size of variable pump between the gearbox and the generators in hydraulic wind turbines; however, the gearbox mechanism was retained. In 2012, the team of Professor Kong from Yanshan University, China, built a hydraulic wind turbine simulation platform, which verified the speed and power control theories of hydraulic wind turbines [20-24]. In summary, several countries have not in the recent past proposed theories on hydraulic wind turbines, constructed actual hydraulic wind turbines, built experimental prototypes, and/or developed initial production. However, hydraulic wind power development is still at its infancy.

\section{Development of hydraulic wind turbine technology}

In 1979, a US patent allowed the wind speed control of mechanical feedback hydraulic wind turbines [25]; however, the control accuracy was low. In 2005, a Canadian patent [26] created turbines that can control displacement in case of load over speed during start-up; however, the displacement could be out of control even when the unit
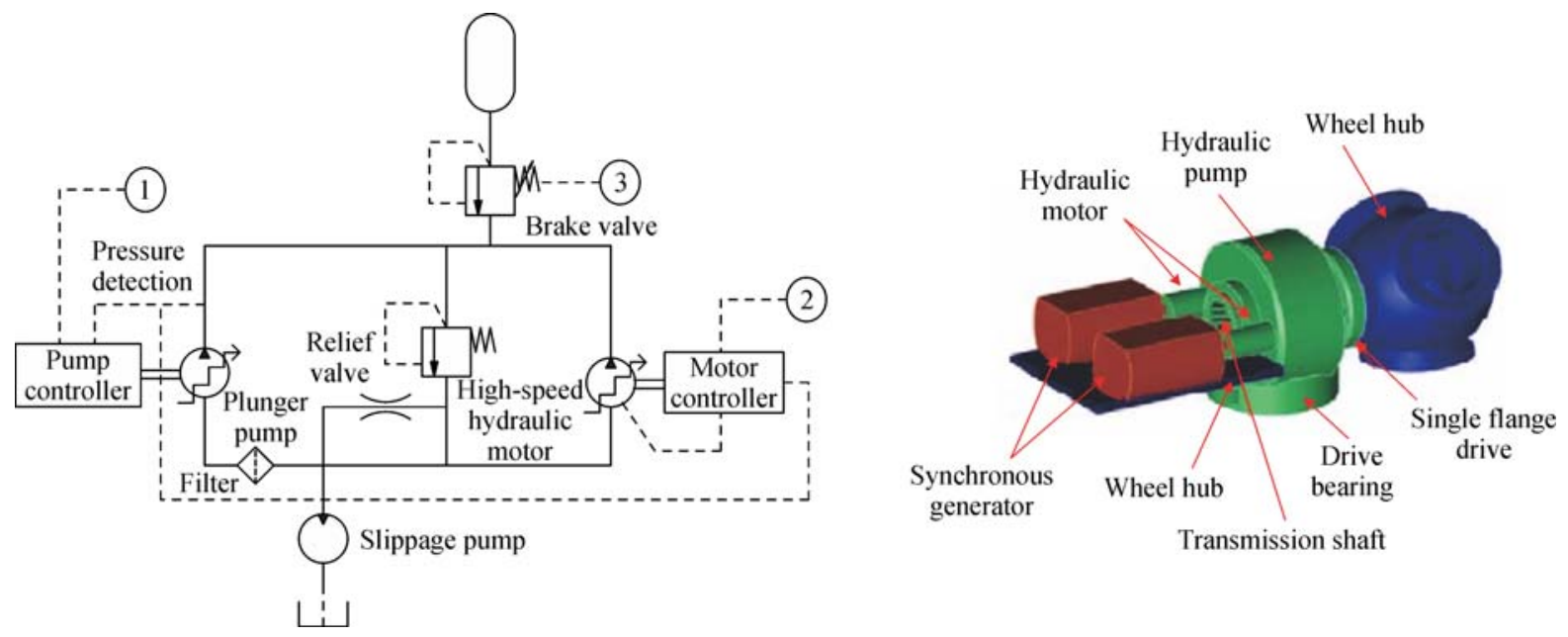

Fig. 2 Diagram of the hydraulic wind power technology model of Artemis Intelligent Power Ltd. [13]
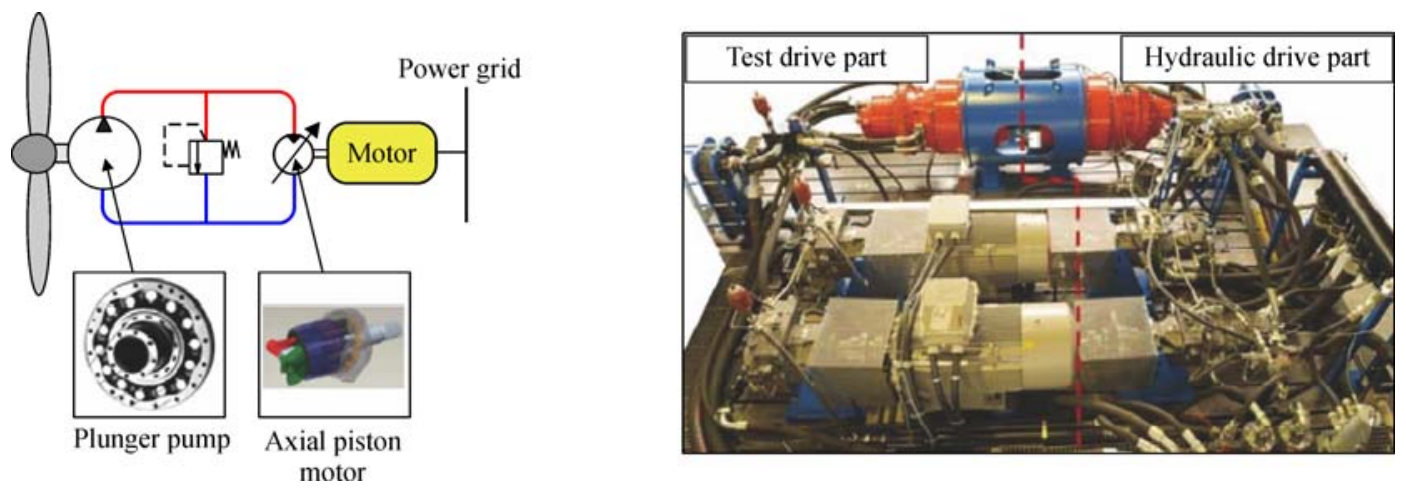

Fig. 3 Diagram of the generator test system of RWTH Aachen University [13] 
was working normally. Thus, in 2008, a Norwegian patent [27] established a power transmission control that improved the efficiency of power generation systems. In 2010, a Chinese patent [28] proposed a gearless frequencystabilization method for hydraulic control; the method used power box deployment, collectors and other devices, resulting in a more complex system. In 2007, an energy equipment company in China introduced a set of hydraulic wind turbine technologies from Nordwind Company in Germany, but no report is available. In 2013, Professor Kong from Yanshan University, China, proposed a speed control for hydraulic wind turbines, established the hydraulic wind power equipment control model, and verified it experimentally [24]. In 2016, Zhang et al. [29] further optimized the control model and obtained a more accurate and efficient control system. In 2014, the Energy Systems and Power Electronics Laboratory of the Indiana University-Purdue University Indianapolis (IUPUI) in the US constructed a hydraulic wind power system model that can resist fluctuations of high and low wind speeds by adjusting the simplified second-order model parameters [30]. In 2015, experiments that considered the proportional valve were verified [31], although it remains in the theoretical verification stage because of the lack of a mature product. Therefore, wind power control technology requires further investigation.

\subsection{Wind speed model}

Many studies worldwide have explored wind speed frequency distribution. At present, the Weibull distribution is considered an appropriate wind speed model. However, this model only reflects the wind speed distribution for more than $10 \mathrm{~min}$, which is unsuitable for studying the coupling of the dynamic characteristics of wind turbines $[32,33]$. The von Karman spectrum can accurately represent wind-tunnel turbulence but not atmospheric turbulence. The Kaimal spectral model is used to describe the power spectral density of wind speed turbulence in wind power research [34-37]. The autoregressive moving average (ARMA) model combines an autoregressive model (AR model) and a moving average model (MA model). However, the AR model is more widely used, although the ARMA model possesses higher simulation efficiency, as its simulation speed can be adapted to the dynamic simulation requirements for power and wind power systems [38-41].

To describe wind speed accurately, the wind speed model is simplified into four main components of wind: Basic wind, gradient wind, gusts, and random wind [4245]. The actual wind speed curve in the simulation and in real short time can be depicted by Fig. 4 [21] by synthesizing these four components of wind speed. As shown, the actual wind speed can be successfully simulated by the mathematical model.

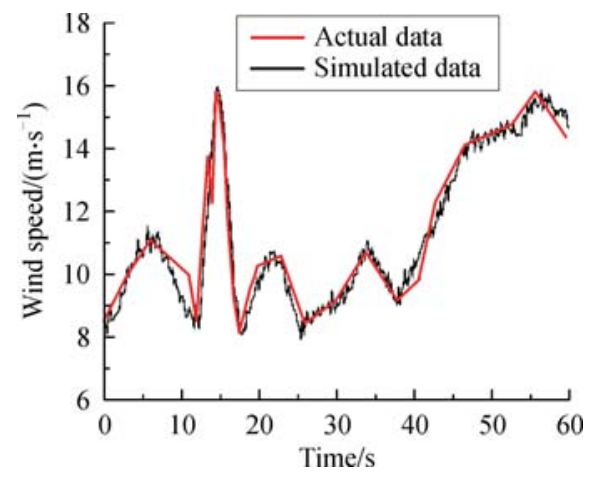

Fig. 4 Actual wind speed curve [21]

\subsection{Fan model}

When moving wind passes through the fan, it decreases in speed. The model is simplified as an air flow tube, as shown in Fig. 5. The rear segment of the flow tube expands to accommodate the reduction of air so that the air is not compressed [46,47]. Kinetic energy drives the rotation of the turbine. The pressure, and not the wind speed, mutates. As shown in Fig. 6, the wind speed decreases, the kinetic energy transforms into mechanical energy, and wind static pressure remains unchanged. However, the wind kinetic energy of the turbine does not change before and after the converted mutation-reduced static pressure into the mechanical energy of the wind machine. When the coefficient value induced by axial flow is $1 / 3$, the wind turbine input power reaches the theoretical maximum, and the wind energy utilization rate is $8 / 9$ [48,49].

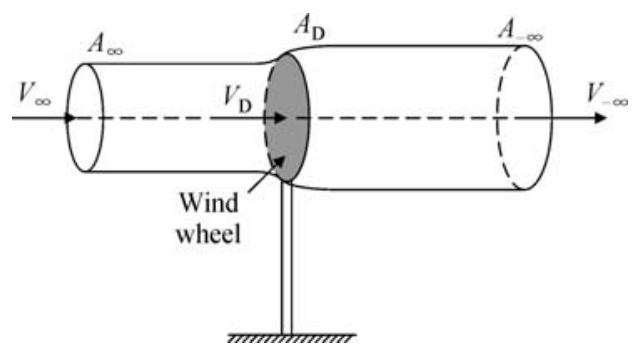

Fig. 5 Flow tube diagram

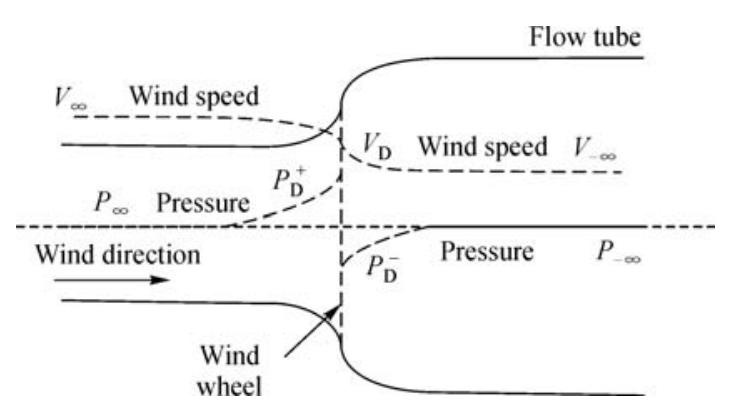

Fig. 6 Air flow and pressure through the flow tube 
Under certain wind speeds, the wind turbine achieves the best speed, and the output power reaches the maximum value. As the wind speed increases, the wind turbine torque initially increases subsequently then decreases. Figures 7 and 8 illustrate the wind turbine power characteristic curve and the starting power characteristic curve under certain speeds [49-51]. In Figs. 7 and 8, $P$ is the output power of the wind turbine, $T$ is the output torque of the wind turbine, and $n$ is the rotate speed of the wind turbine.

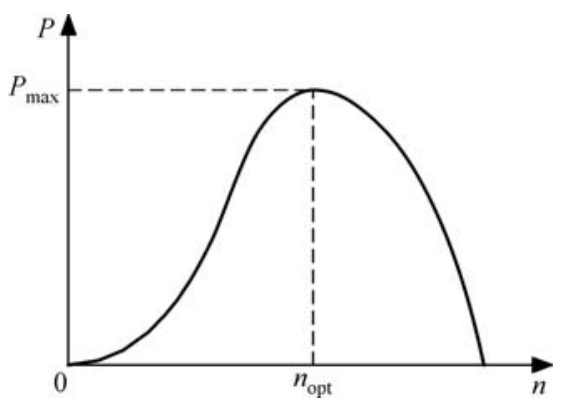

Fig. 7 Wind turbine power characteristic curve

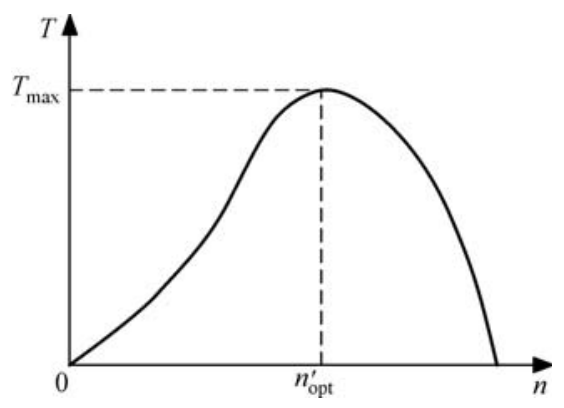

Fig. 8 Wind turbine torque curve

The operation of the hydraulic wind turbine is divided into four phases according to different conditions, as illustrated in the output power curve in Fig. 9, in which $P$ is the output power of the wind turbine and $v$ is the speed of

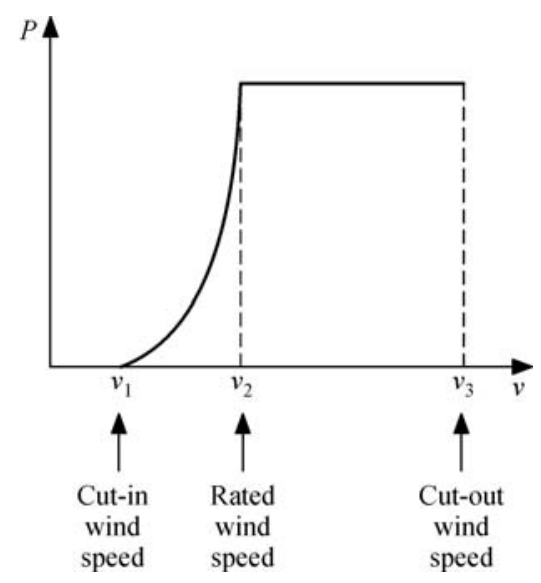

Fig. 9 Relationship between wind speed and output power the wind. When the wind speed is below the cut-in speed, the generator stops working, the turbine remains in shutdown state, and the output power is zero. When the wind speed is greater than the cut-in speed but less than the rated speed, the wind turbine control system operates normally, and the turbine drives the rotation of the fixed pump. A constant speed output of the motor can be achieved by controlling the swash plate angle of the variable motor, and the output power of the synchronous generator increases as the wind speed intensifies. When the wind speed is greater than the rated wind speed but less than the cut-out wind speed, the wind turbine control system operates, and the generator outputs rated power. However, when the wind speed is greater than the cut-out wind speed, the wind turbine control system stops functioning and proceeds in a locked state, and the output power turns zero.

\subsection{Main drive system}

Figure 10 shows the principle underlying the hydraulic wind turbine using a fixed-quantity pump and variable hydraulic motor volume timing circuit as the main transmission system. Changing the displacement of the variable motor adjusts the hydraulic transmission ratio, controls the operation of the generator under synchronous speed, and facilitates the application of the electrically excited synchronous generator in wind power generation. The characteristic curve of the volume timing circuit of the fixed-quantity pump and variable hydraulic motor system is shown in Fig. 11. When the output flow and the pressure in the fixed-quantity pump are constant, the speed is inversely proportional to the displacement of the variable motor, the torque is proportional to the displacement of the hydraulic motor, and the output power is constant.

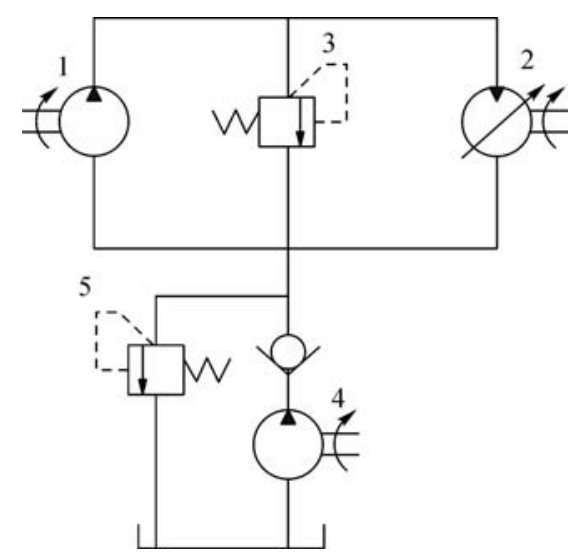

Fig. 10 Volume timing circuit of the fixed-quantity pump and variable hydraulic motor system

For hydraulic energy transfer, the Energy Systems and Power Electronics Laboratory of IUPUI developed a 


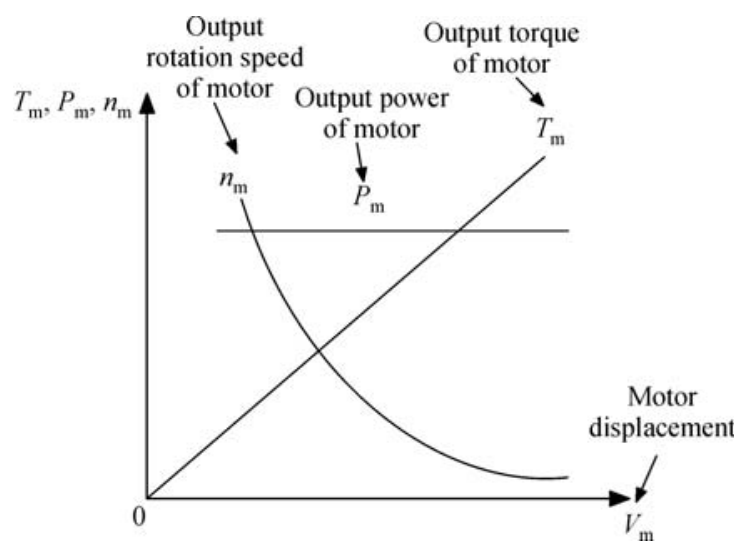

Fig. 11 Characteristic curve of the volume timing circuit of the fixed-quantity pump and variable hydraulic motor system

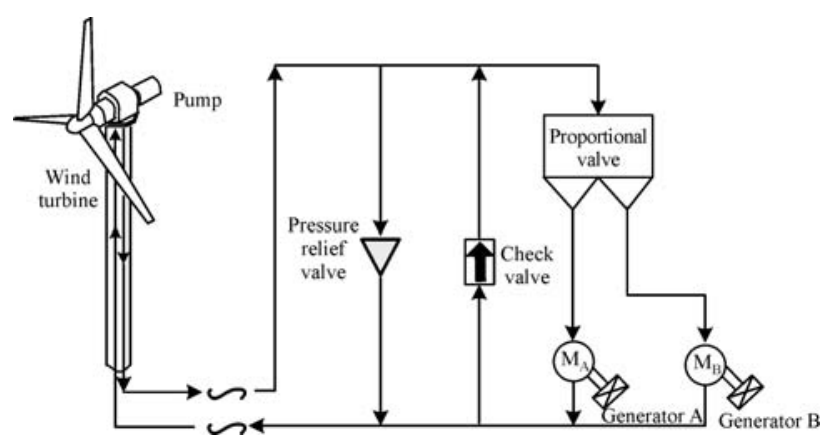

Fig. 12 Schematic of the hydraulic wind power transfer system built by Energy Systems and Power Electronics Laboratory of IUPUI [30]

control system for a nonlinear model of a hydraulic wind power transfer system. The designed controller was implemented to regulate the flow in the proportional valve. The schematic of the structure is shown in Fig. 12, and its experimental setup is shown in Fig. 13 [30].

The mathematical model is established as follows [31]:

\subsubsection{Pump}

A fixed position displacement pump is used. The governing equation of the pump flow rate is described as follows $[52,53]$ :

$$
Q_{\mathrm{p}}=D_{\mathrm{p}} \omega_{\mathrm{p}}-\frac{C_{\mathrm{s}} D_{\mathrm{p}}}{\mu} P_{\mathrm{p}}
$$

where $Q_{\mathrm{p}}$ is the actual delivered flow rate, $D_{\mathrm{p}}, \omega_{\mathrm{p}}$, and $P_{\mathrm{p}}$ are the pump displacement, angular velocity, and differential pressure across the pump, respectively, $C_{\mathrm{s}}$ and $\mu$ are the slippage coefficient and absolute viscosity, respectively; and $C_{\mathrm{s}}$ is a constant term, provided that the internal structure of the pump does not change [54].

\subsubsection{Hydraulic motor}

The following governing equation for the motor flow is similar to the pump's flow equation, but with the motor leakage flow, $K_{\mathrm{ms}}$, as the additive term $[52,53]$ :

$$
Q_{\mathrm{m}}=D_{\mathrm{m}} \omega_{\mathrm{m}}+K_{\mathrm{ms}} U_{\mathrm{m}},
$$

where $U_{\mathrm{m}}$ is the pressure differential across the motor $[52,53,55]$ and the other terms are the same as those of the pump flow equation.

\subsubsection{Proportional flow control valve}

A proportional valve can be utilized to control the flow at the motor inlets. At each outlet of the valve, the passing flow $[52,53]$ can be calculated as follows:

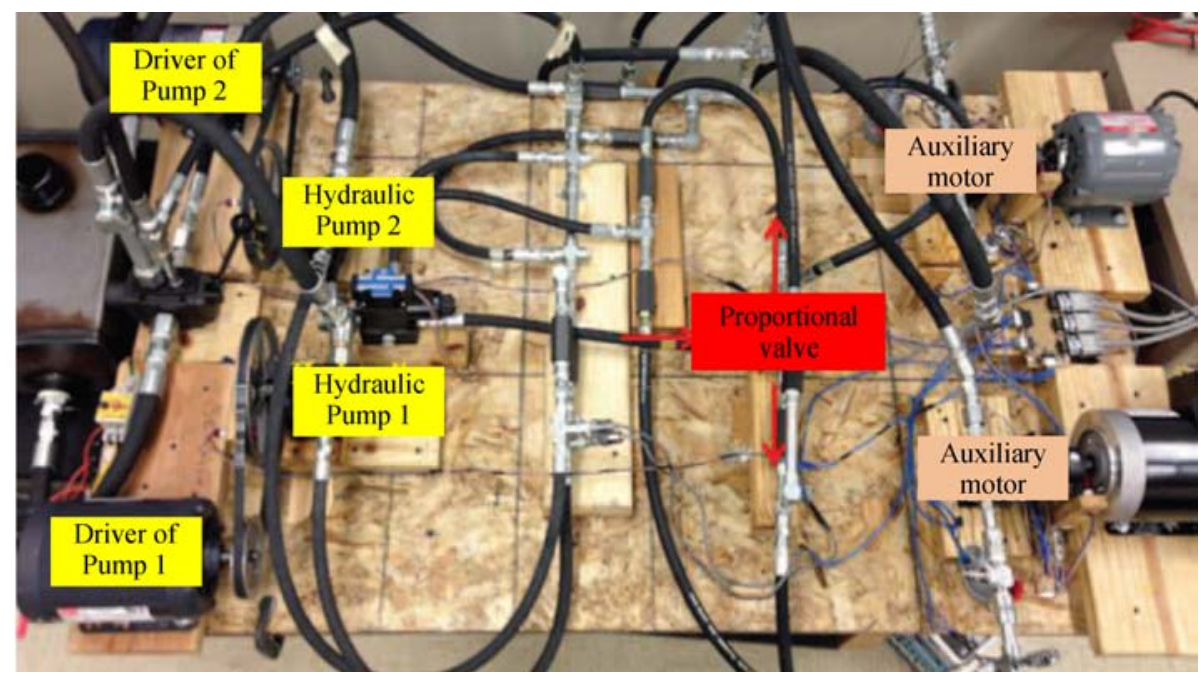

Fig. 13 Experimental setup of the hydraulic wind power transfer system of the Energy Systems and Power Electronics Laboratory [30] 


$$
Q=C_{\mathrm{d}} A \sqrt{\frac{2 \Delta U}{\rho}},
$$

where $C_{\mathrm{d}}$ is the discharge coefficient, $A$ is the orifice area, $\Delta U$ is the pressure difference across the orifice, and $\rho$ is the fluid density.

\subsubsection{Compressibility (hose dynamics)}

The fluid compressibility model elucidates the relationship between the pressure changes and the amount of compressed flow in a control volume. This relationship can be expressed as follows [56,57]:

$$
\frac{\mathrm{d} U}{\mathrm{~d} t}=\frac{\beta}{V} Q_{\text {comp }}=\frac{\beta}{V}\left(Q_{\text {in }}-Q_{\text {out }}\right),
$$

where $U$ is the pressure present in the hydraulic circuit segment, $\beta$ is the constant fluid bulk modulus, and $Q_{\text {in }}$ and $Q_{\text {out }}$ are the flows entering and exiting a control volume, respectively. For power transmission analysis, the rates of pressure variations in the pump, motors, and control valves are necessary, so that the effective control volumes are those located in between pump, motors and valves. The circuit and the boundary of the control volumes are shown in Fig. 14 [31]. In Fig. 14, $V$ is the volume of the circuit.

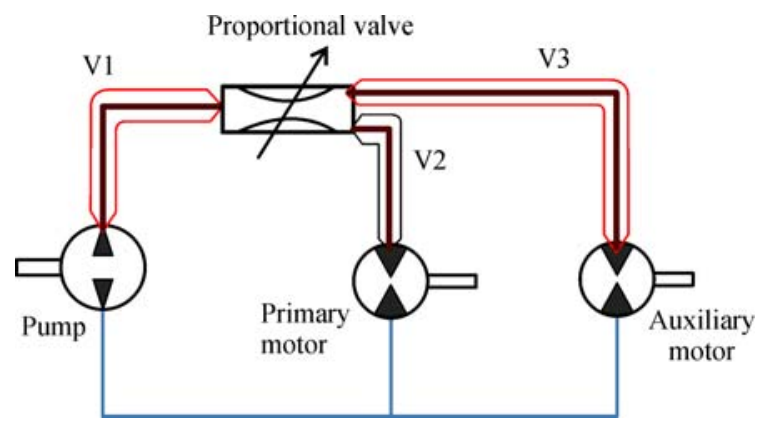

Fig. 14 Schematic of the three piping parts of the circuit on which the compressibility equations are used [31]

By using the established mathematical model and on the basis of the equations deduced above, Deldar et al. [31] compared the obtained results with the experimental results, as shown in Figs. 15 and 16.

As shown in Fig. 15, the primary motor speed is constant, which agrees with the governing equation. However, in Fig. 16, when the primary motor speed is constant, regardless of the pump speed, the excessive flow due to the high pump speed is directed toward the auxiliary motor, causing an obvious speed increase.

\subsection{Control technology of the simplified model system}

As shown in Fig. 1, the hydraulic wind turbine system can be simplified as a variable-displacement pump and

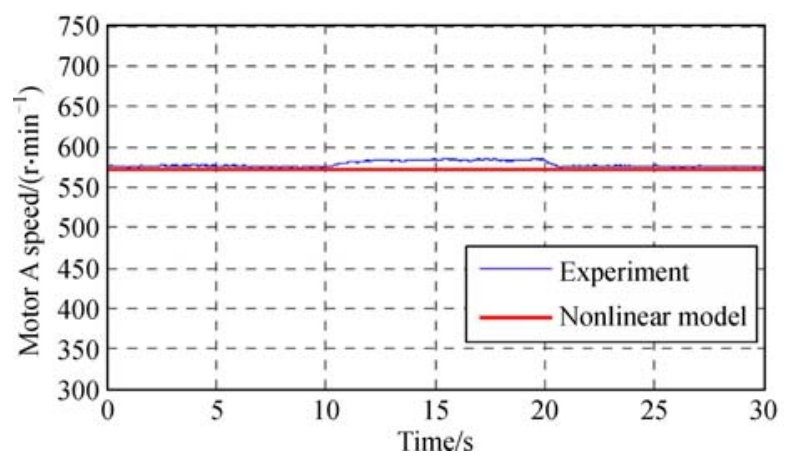

Fig. 15 Primary motor velocity profile as a result of wind speed step changes [31]

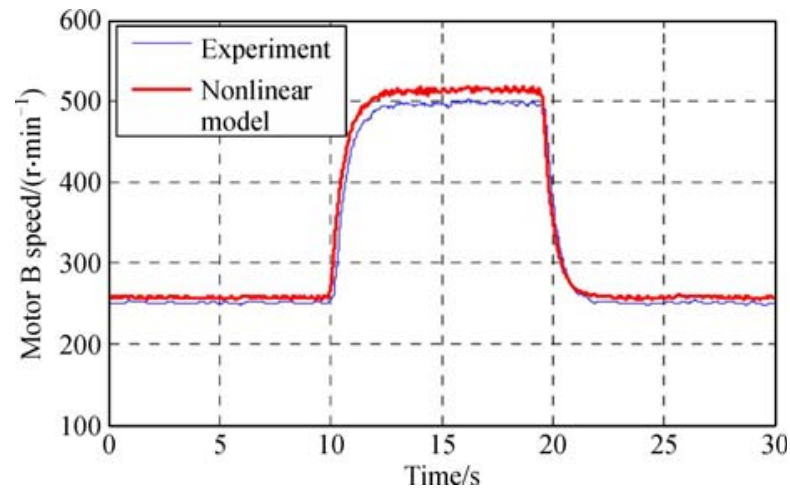

Fig. 16 Auxiliary motor velocity profile as a result of wind speed step changes [31]

constant-displacement motor system. In valve-controlled hydraulic systems, overflow loss or damper loss could occur, resulting in an inadequately high hydraulic drive efficiency [48]. In comparison, overflow loss does not occur in a variable-displacement pump and constantdisplacement motor system. The hydraulic wind turbine system requires a variable speed input and a constant speed output, and the system includes a constant pressure state and a constant flow state [22]. The constant working state of the variable-displacement pump and constant-displacement motor system is the key to the steady-speed control. Indirect feedback flow can be utilized to realize closedloop speed control directly for steady-speed control. On this basis, the output speed can be adjusted to control the generated power [24].

Gelazanskas et al. [58] from Lancaster University recently summarized the controlled use of a hybrid flow battery as well as thermal and hydro power plant systems by proposing a hydraulic wind power balancing technique using thermal power plant (TPP), hydro power plant (HPP), flow batteries (FB) control strategies. This technique presented positive results in balancing wind power. Oppositely charged electrolytes are pumped through separate compartments, and the reaction occurs in a special ionic membrane, as shown in Figs. 17 and 18. 


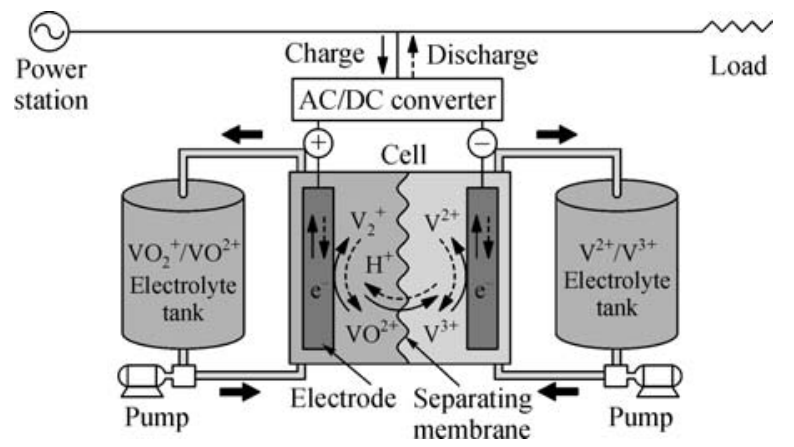

Fig. 17 Configuration of a flow battery [58]

\section{Advantages and limitations of hydraulic wind turbines}

\subsection{Advantages}

The hydraulic wind turbine has been universally recognized as a new-generation wind power generation equipment. Compared with conventional models, the main transmission systems of hydraulic wind turbines present the following advantages:

1) A two-blade wind turbine is optional. The rotation speed is high. Compared with the traditional model, the hydraulic wind turbine generator has a relatively low load torque when the output power is equal.
2) The system is in the form of hydraulic transmission systems. The transmission ratio is adjustable in real time. The system is highly flexible, and its flexible control can suppress the effect of wind fluctuations on power efficiency.

3) The system can be applied to electrically excited synchronous generators in wind turbines. The frequency inverter device is eliminated, and the shock to the grid is reduced without harmonics when connected to the grid in quasi-synchronization mode. The power factor can be adjusted according to the grid needs with the issued active and reactive power. The electrically excited synchronous generator has a strong low-voltage ride-through capability without additional hardware.

4) The gearbox is eliminated. The power consumption is reduced, thereby significantly reducing the weight of the wind turbine. The installation is lower. The system is welladapted to the needs of both onshore and offshore wind turbines.

\subsection{Limitations}

Leakage is the main problem of hydraulic wind turbine, even of the entire hydraulic system. The liquid transmission medium in the hydraulic system is inevitably susceptible to leakage. Moreover, the hydraulic oil is not absolutely incompressible, suggesting that the hydraulic system should not to be used when the transmission ratio

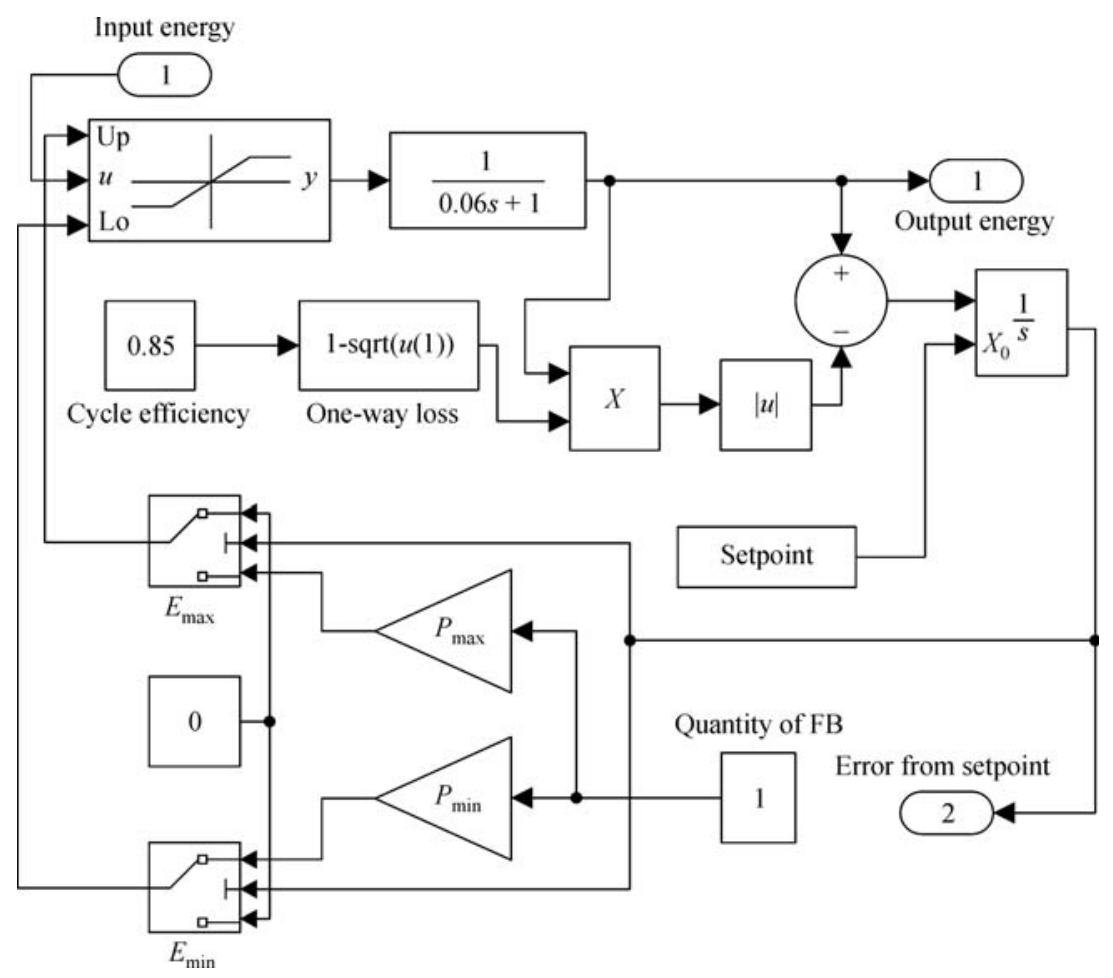

Fig. 18 The structure of the flow battery model [58]. "up" and "lo" are the up and low limit of the input energy signal, respectively, " $u$ " means the input Laplace signal; $E_{\max }$ and $E_{\min }$ are the max and min of the energy, respectively; $P_{\max }$ and $P_{\min }$ are the max and min of the power, respectively 
needs to be precise. To overcome these problems, the manufacturing precision of the hydraulic components should be high; however, this results in the high cost of wind turbines. Decreased power and maintenance difficulties are other limitations that should be addressed.

\section{Conclusions}

Although many countries worldwide have conducted theoretical research and prototype experiments on the main hydraulic transmission control systems of hydraulic wind turbines, this research area is still in its infancy in China. The complete introduction of foreign hydraulic wind turbine technology is extremely costly, and local users are likely to experience difficulty in mastering core technologies. Therefore, research on a localized model is encouraged for the development of a hydraulic transmission control system for hydraulic wind turbines with improved efficiency and flexibility. The system can be connected to the grid by using an electrically excited synchronous generator. The system can achieve power generation, optimum power tracking, and low-voltage ride through. It can eliminate the use of a gearbox and a rectifier-inverter device, reduce wind turbine weight, and lower installation cost. Hydraulic wind turbines will be an emerging development direction of wind turbines.

Open Access This article is distributed under the terms of the Creative Commons Attribution 4.0 International License (http://creativecommons.org/ licenses/by/4.0/), which permits unrestricted use, distribution, and reproduction in any medium, provided you give appropriate credit to the original author(s) and the source, provide a link to the Creative Commons license, and indicate if changes were made.

\section{References}

1. Jelavić M, Petrović V, Perić N. Estimation based individual pitch control of wind turbine. Automatika: Časopis Za Automatiku Mjerenje Elektroniku Računarstvo I Komunikacije, 2010, 51(2): 181-192

2. Muyeen S M, Takahashi R, Murata T, et al. Low voltage ride through capability enhancement of fixed speed wind generator. In: Proceedings of PowerTech. Bucharest: IEEE, 2009, 1-6

3. Teninge A, Roye D, Bacha S, et al. Low voltage ride-through capabilities of wind plant combining different turbine technologies. In: Proceedings of 13th European Conference on Power Electronics and Applications. IEEE, 2009, 1-9

4. Albadi M H, El-Saadany E F. Wind turbines capacity factor modeling-A novel approach. IEEE Transactions on Power Systems, 2009, 24(3): 1637-1638

5. Yang W, Tavner P J, Wilkinson M R. Condition monitoring and fault diagnosis of a wind turbine synchronous generator drive train. IET Renewable Power Generation, 2009, 3(1): 1-11

6. Geng H, Yang G. Robust pitch controller for output power levelling of variable-speed variable-pitch wind turbine generator systems. IET Renewable Power Generation, 2009, 3(2): 168-179

7. Kusiak A, Zhang Z, Li M. Optimization of wind turbine performance with data-driven models. IEEE Transactions on Sustainable Energy, 2010, 1(2): 66-76

8. Chen P, Siano P, Bak-Jensen B, et al. Stochastic optimization of wind turbine power factor using stochastic model of wind power. IEEE Transactions on Sustainable Energy, 2010, 1(1): 19-29

9. Bao G, Shi J, Jiang J. A survy on variable speed constant frequency wind power systems with direct coupled generators. Small \& Special Electrical Machines, 2008, 36(8): 52-55 (in Chinese)

10. Hamzehlouia S, Izadian A. Modeling of hydraulic wind power transfers. In: Proceedings of 2012 IEEE Power and Energy Conference at Illinois. IEEE, 2012, 1-6

11. Murrenhoff $H$. Recent sustainability related research results in fluid power. In: Proceedings of the 2011 International Conference on Fluid Power and Mechatronics. IEEE, 2011, 991-1001

12. Kong X, Ai C, Wang J. A summary on the control system of hydrostatic drive train for wind turbines. Chinese Hydraulics \& Pneumatics, 2013, 0(01): 1-6 (in Chinese)

13. Ai C. Research on speed control and power control of hydraulic type wind turbine. Dissertation for the Doctoral Degree. Qinhuangdao: Yanshan University, 2012

14. Lei F. Designing and debugging of wind power hydraulic assembly system. China Science \& Technology Overview, 2016, 3(6): 59 (in Chinese)

15. Yuan Y. Research on switched reluctance four port electromechanical energy transducer used for wind power. Dissertation for the Master's Degree. Harbin: Harbin Institute of Technology, 2008 (in Chinese)

16. Whitby R D. Hydraulic fluids in wind turbines. Tribology \& Lubrication Technology, 2010, 66(3): 72-73

17. Murrenhoff H. Servohydraulik - Geregelte Hydraulische Antriebe. 3rd ed. Aachen: RWTH, 2008

18. Kohmascher T. Modelling analysis and interpretation of hydraulic system concepts. Dissertation for the Doctoral Degree. Nord RheinWestfalen: Rheinisch-Westfaelische Technische Hochschule Aachen, 2008

19. Chen J, Zhou Q. Application of hydraulic drive in wind power generation system. Movable Power Station \& Vehicle, 2011, 42(1): 30-32 (in Chinese)

20. Yao J, Li B, Kong X, et al. Displacement and dual-pressure compound control for fast forging hydraulic system. Journal of Mechanical Science and Technology, 2016, 30(1): 353-363

21. Ai C, Chen W, Kong X, et al. Maximum power point tracking control of hydraulic type wind turbine based on feedback linearization. Control Theory \& Applications, 2015, 32(6): 778786 (in Chinese)

22. Kong A, Zhang X, Hao G. Simulation study on constant speed output control of fixed displacement pump-variable displacement motor hydraulic system. In: Proceedings of the 2011 International Conference on Fluid Power and Mechatronics. IEEE, 2011, 276281

23. Kong X, Ba K, Yu B, et al. Force control compensation method with variable load stiffness and damping of the hydraulic drive unit force control system. Chinese Journal of Mechanical Engineering, 2016, 


\section{9(3): 454-464}

24. Kong X, Ba K, Yu B, et al. Trajectory sensitivity analysis of first order and second order on position control system of highly integrated valve-controlled cylinder. Journal of Mechanical Science and Technology, 2015, 29(10): 4445-4464

25. Schachles. US Patent, 4503673, 1979-05-25

26. Global M L H. Canada Patent, 03816799, 2005-09-14

27. Chapp Drive Company. Norway Patent, 200680040609.5. 2008-1105

28. Chen Z, Wen X. China Patent, 201010106583.8, 2010-08-04

29. Zhang Y, Kong X, Hao L, et al. Controls of hydraulic wind turbine. In: Proceedings of 2015 International Conference on Mechanical Engineering and Electrical Systems. EDP Sciences, 2016

30. Vaezi M, Izadian A. Control of a hydraulic wind power transfer system under disturbances. In: Proceedings of International Conference on Renewable Energy Research and Application. IEEE, 2014, 886-890

31. Deldar M, Izadian A, Vaezi M, et al. Modeling of a hydraulic wind power transfer utilizing a proportional valve. IEEE Transactions on Industry Applications, 2015, 51(2): 1837-1844

32. Seguro J V, Lambert T W. Modern estimation of the parameters of the Weibull wind speed distribution for wind energy analysis. Journal of Wind Engineering and Industrial Aerodynamics, 2000, 85 (1): $75-84$

33. Zhang X. Parameter estimate method application of Weibull distribution. Acta Meteorologica Sinica, 1996, 54(1): 108-116 (in Chinese)

34. Zhi L, Li Q, Hu F. Field measurements of strong wind characteristics near ground in urban area. Journal of Hunan University (Natural Sciences), 2009, 36(2): 8-12 (in Chinese)

35. Sun C. Study of control methods of wind power system. Dissertation for the Doctoral Degree. Changsha: Hunan University, 2008, 85-90 (in Chinese)

36. Sun J. Research on wind farm modeling and simulating. Dissertation for the Master's Degree. Beijing: Tsinghua University, 2004, 19-23 (in Chinese)

37. Welfonder E, Neifer R, Spanner M. Development and experimental identification of dynamic models for wind turbines. Control Engineering Practice, 1997, 5(1): 63-73

38. Lojowska A, Kurowicka D, Papaefthymiou G, et al. Advantages of ARMA-GARCH wind speed time series modeling. In: Proceedings of IEEE 11th International Conference on Probabilistic Methods Applied to Power Systems. IEEE, 2010, 83-88

39. Wang $X$, Liu X. Application of ARMA time series model. Techniques of Automation and Applications, 2008, 27(8): 65-66 (in Chinese)

40. Nichita C, Luca D, Dakyo B, et al. Large band simulation of the wind speed for real time wind turbine simulators. IEEE Transactions on Energy Conversion, 2002, 17(4): 523-529

41. Abo-Khalil A G, Lee D C. MPPT control of wind generation systems based on estimated wind speed using SVR. IEEE Transactions on Industrial Electronics, 2008, 55(3): 1489-1490

42. He P, Hu S, Huang H, et al. Research on intelligent controller for large-scale wind turbine power generator with active stall and pitch control. Water Power, 2008, 34(12): 100-102 (in Chinese)

43. Yang J. Wind speed model of wind turbine suitable for dynamic analysis. Journal of Southwest University of Science \& Technology, 2010, 25(1): 39-44 (in Chinese)

44. Wu X, Zhang X, Yin Y, et al. Application of models of the wind turbine induction generators (WTIGs) to wind power system dynamic stability analysis. Power System Technology, 1998, 22 (6): 68-72 (in Chinese)

45. Anderson P M, Bose A. Stability simulation of wind turbine systems. IEEE Transactions on Power Apparatus and Systems, 1983, PAS-102(12): 3791-3795

46. Yang X. Research on the performance of wind turbine drive train. Dissertation for the Master's Degree. Chongqing: Chongqing University, 2008, 7-9 (in Chinese)

47. Kishinami K, Suzuki J, Sugiyama H, et al. Theoretical and Experimental Study on Aerodynamic Characteristics of H. A. W. T.: In case of NACA44 series blade equipped with a single-slotted flap. In: Proceedings of Symposium on Environmental Engineering. The Japan Society of Mechanical Engineers, 2003, 438-441

48. Nikranjbar A, Shahrbabaki A N. Simulation and control of wind turbine using hydrostatic drive train. Majlesi Journal of Energy Management, 2013, 2(2): 12-17

49. Wang Z. Modern Wind Power Technology and Its Engineering Application. Beijing: Publishing House of Electronics Industry, 2010, 24-27 (in Chinese)

50. Jiang Z, Yu X. Modeling and control of an integrated wind power generation and energy storage system. In: Proceedings of IEEE Power \& Energy Society General Meeting. IEEE, 2009, 1-8

51. Burton T, Sharpe D, Jenkins N, et al. Wind Energy Handbook, 2011

52. Fitch E C, Hong I T. Hydraulic Component Design and Selection. Stillwater: Bardyne Inc., 2004

53. Merritt H E. Hydraulic Control Systems. New York: John Wiley \& Sons, 1967

54. Blackburn J F. Fluid Power Control. Cambridge: MIT Press, 1969

55. Gorbeshko M. Development of mathematical models for the hydraulic machinery of systems controlling the moving components. Hydrotechnical Construction, 1997, 31(12): 745-750

56. Manring N. Hydraulic Control Systems. New York: John Wiley \& Sons, 2005

57. Akkaya A V. Effect of bulk modulus on performance of a hydrostatic transmission control system. Sadhana, 2006, 31(5): 543-556

58. Gelazanskas L, Baranauskas A, Gamage K A A, et al. Hybrid wind power balance control strategy using thermal power, hydro power and flow batteries. International Journal of Electrical Power \& Energy Systems, 2016, 74: 310-321 